\title{
COGNITIVE SEMIOTICS IN EDUCATION
}

\author{
Donald J. Cunningham and Paul E. Kehle'
}

Logic, in its general sense, is... only another name for semiotic ( $\{$ sémeiötiké\}), the quasi-necessary, or formal, doctrine of signs. By describing the doctrine as "quasi-necessary," or formal, I mean that we observe the characters of such signs as we know, and from such an observation, by a process which I will not object to naming Abstraction, we are led to statements, eminently fallible, and therefore in one sense by no means necessary, as to what must be the characters of all signs used by a "scientific" intelligence, that is to say, by an intelligence capable of learning by experience. As to that process of abstraction, it is itself a sort of observation... [The person] makes in his imagination a sort of skeleton diagram, or outline sketch..., considers what modifications the hypothetical state of things would require to be made in that picture, and then examines it, that is, observes what he has imagined... By such a process, which is at bottom very much like mathematical reasoning, we can reach conclusions as to what would be true of signs in all cases, so long as the intelligence using them was scientific. The modes of thought of a God, who should possess an intuitive omniscience superseding reason, are put out of the question. Now the whole process of development among the community of students of those formulations by abstractive observation and reasoning of the truths which must hold good of all signs used by a

I Indiana University, Bloomington. 
scientific intelligence is an observational science, like any other positive science, notwithstanding its strong contrast to all the special sciences which arises from its aiming to find out what must be and not merely what is in the actual world'. (Peirce 2.227, emphases in original)

In this paper, we will propose that within this quotation and throughout the work of Charles Sanders Peirce, there is a strongly implied if not fully articulated a model of cognition in general, and within educational settings, learning in particular that, if followed more deliberately, would promote something of a revolution in the instructional sciences. Given our limitations of space, we will focus on Peirce's work on cognition and inquiry as they relate to learning. We will argue that Peirce was able to foresee, in the late 19th and early 20th century, the principles of collective and meaning-driven models of learning, cognition, and inquiry that are only now emerging in psychology and education. Peirce's inability to communicate and realize the practical implications of his semiotic ideas into culture, and in our case pedagogy, during his lifetime was due in no small measure to the times in which he lived, to the lack of contemporary models or embodiments of his ideas. We feel that it is now time!

To advance our thesis, we first outline some key concepts from Peirce, embedded in the quotation above, such as logic, reasoning, abstraction and learning. We will then use these notions to examine empirically some of the characteristics of mathematical problem solving by viewing it through a semiotic lens. In closing we offer examples of pedagogical insights we believe are directly supported by a semiotic perspective, insights that lend greater specificity to constructivist theories of learning and suggest subtle but eventually radical changes in instruction.

\section{Learning, Logic and Semiotic}

In the paragraph quoted, Peirce equates logic and semiotic, a stance that will be unfamiliar to those who remember their undergraduate philosophy class where logic was a tool for reaching a correct deductive inference and/or for manipulating abstract symbols.

1 C.S. PeIrCe, Collected papers of Charles Sanders Peirce, C. HARTSHORNE and P. WeIss (eds), Cambridge, MA, Harvard University Press, 1931-1965, 2.227, emphases in original. 
Peirce's view is much grander-logic is the key to understanding reality itself: "Therefore, we do not ask what really is, but only what appears to every one of us in every minute of our lives"l. While Peirce is describing the actions of someone engaging in logic/semiotics to understand reality (i.e., a semiotician), in point of fact he is also describing a process that underlies ordinary, everyday cognition: semiosis.

As stated above, Peirce proposes that we observe the character of signs that we perceive and, through a process of reasoning, move towards structures that embody what must be true of those signs for them to make sense to us as we learn and grow. The perceptive reader will notice that we have changed the wording of Peirce's statement but we believe our interpretation to be consistent with his views. For example, we substituted the word perceive for the word know. Here we seek to reconcile two famous assertions from Peirce, that the "universe is perfused with signs, if it is not composed exclusively of signs" 2 and "a sign is not a sign unless it translates itself into another sign in which it is more fully developed" 3 . So signs are everywhere, but they only impact us if we take notice of them in some way, if they are a part of or can be integrated within the structures we build to represent the world. We substituted the word reasoning for abstraction to avoid the, we believe, incorrect assumption that the process of signification (taking one thing to stand for another) is limited to a movement from the concrete to the abstract. The movement could just as easily be from abstract to concrete or from one sign system to another. The important point, to be elaborated shortly, is that cognition can be seen as semiosis, the building up of structures of signs through experience ${ }^{4}$.

Peirce's use of the word statements might be misinterpreted as limited to verbal structures only, hence our substitution of the word structures. These structures are "eminently fallible." They represent our current belief about what must be the character of the signs under consideration. The concept of belief is key in Peirce's view and he spoke of a semiosis in general as a movement toward "fixing" a

1 Ibid., 2.84 .

2 Ibid., 5.448 .

3 Ibid., 5.594.

4 D.J. Cunningham, "Cognition as semiosis: The role of inference", Theory and Psychology, 8, 1998, pp. 827-840. 
belief. The converse of belief is doubt and Peirce was very explicit in drawing the distinction between them:

We generally know when we wish to ask a question and when
we wish to pronounce a judgment, for there is a dissimilarity
between the sensation of doubting and that of believing. But
this is not all that distinguishes doubt from belief. There is a
practical difference. Our beliefs guide our desires and shape
our actions... Doubt is an uneasy and dissatisfied state from
which we struggle to free ourselves and pass into the state of
belief; while (belief) is a calm and satisfactory state which we
do not wish to avoid, or to change to a belief in anything else.
On the contrary, we cling tenaciously, not merely to believing,
but to believing just what we do believe!

Peirce called such doubt "genuine doubt". As such it is situated in our experience, not a methodological ploy as in Descartes' use of doubt. Doubt arises when the structures we have created, our current beliefs, do not account for some experience, when the character of signs does not fit our understanding. Peirce proposed four methods of resolving doubt and fixing beliefs: tenacity, authority, a priori, and experiment. Briefly, tenacity is invoked whenever one holds on to beliefs in the face of doubt and asserts that the beliefs will eventually accommodate the doubtful event. We use the method of authority to fix beliefs when we accept the beliefs of authority figures like teachers or scientists. Nowhere is the method of authority more widely used, and abused, than in the field of education. The a prior $i$ method is invoked when our beliefs change in the context of already existing structure of beliefs, a conceptual coherence to a worldview that has served us well so far. The three methods described so far all resolve doubt by opinion, stubbornly maintained, taken from others, or reasoned from premises. The fourth method, which Peirce preferred, is the method of experiment, where one seeks to remove doubt by collecting observations, generating potential hypotheses to account for the surprising experience, and reaching a conclusion based upon the interplay of inferential processes.

Inference, in fact, is implicated in all the methods of resolving doubt. Elsewhere ${ }^{2}$ Peirce describes three modes of inference

1 C.S. PEIRCE, op. cit., 5.370-372.

${ }^{2}$ E.g., ibid., 5.145. 
-abduction, induction and deduction- through which observers can build and work with structures of signs:

Deduction is the only necessary reasoning. It is the reasoning of mathematics. It starts from a hypothesis, the truth or falsity of which has nothing to do with the reasoning; and of course its conclusions are equally ideal. The ordinary use of the doctrine of chances is necessary reasoning, although it is reasoning concerning probabilities. Induction is the experimental testing of a theory. The justification of it is that, although the conclusion at any stage of the investigation may be more or less erroneous, yet the further application of the same method must correct the error. The only thing that induction accomplishes is to determine the value of a quantity. It sets out with a theory and measures the degree of concordance of that theory with fact. It can never originate any idea whatsoever. No more can deduction. All the ideas of science come to it by way of Abduction. Abduction consists in studying facts and devising a theory to explain them. Its only justification is that if we are ever to understand things at all, it must be in that way'.

In the case of the method of experiment, a surprising experience might lead us to abduce a new hypothesis and examine it deductively to see if it squares with the available facts. Suppose, for example I held the view that individual members of a species tended to be larger in colder climates. Recent data, however, had shown that this was not true of fish. If I engage in abduction I might generate the hypothesis that the original relationship only applies to mammals. If observation showed that hypothesis to be true, then the surprising experience would be a matter of course. Deductively I could link my hypothesis to other varieties of animals and inductively test the consequences. Similar inferential strategies can be observed in a prior $i$, authority and even tenacity.

The validity of our beliefs is tested in accord with Peirce's pragmatic maxim:

Consider what effects, that might conceivably have practical bearings, we conceive the object of our conception to have. Then, our conception of these effects is the whole of our conception of the object ${ }^{2}$.

1 Ibid.

2 Ibid., 5.402. 
If our beliefs are adequate to account for the phenomena before us, then we are satisfied. It is doubt that drives semiosis.

One important source of doubt comes from comparing our beliefs with others. Logic is grounded in the collective nature of semiosis itself, and oriented toward future activity. Peirce's understanding of community was in terms of both the present communities of practice (scientist, citizen, family member, etc.), and the "family" of all participants, past and future as well as present, who have, are and will work on clarifying our ideas and understandings.

Finally, as what anything really is, is what it may finally come to be known to be in the ideal state of complete information, so that reality depends on the ultimate decision of the community; so thought is what it is, only by virtue of its addressing a future thought which is in its value as thought identical with it, though more developed. In this way, the existence of thought now depends on what is to be hereafter; so that it has only a potential existence, dependent on the future thought of the community'.

In summary, we have argued that the subject matter of semiotics is semiosis, the action of signs in all domains of life. Human cognition is accomplished entirely with signs - we have no direct access to the real world. Our understanding of the world is entirely mediated by signs, and therefore to understand human cognition, we must understand the nature of our signs: What is a sign? How is one sign related to another sign? What do signs reveal about the real world? What do they obscure? How are signs formed? What are the ways in which signs can stand for something else? The identification, understanding, and use of signs is a fundamental part of inquiry. In fact, the process of semiotics within inquiry was seen to be an emergent process, and one quite explicitly linked to our cognitive natures:

Symbols grow. They come into being by development out of other signs... We think only in signs. These mental signs are of mixed nature; the symbol-parts of them are called concepts. If a man makes a new symbol, it is by thoughts involving concepts. So it is only out of symbols that new symbols can grow. Omne symbolum de symbolo. A symbol, once in being, spreads among the people. In use and in experience, its

1 Ibid., 5.316. 
meaning grows. Such words as force, law, wealth, marriage, bear for us very different meanings from those they bore for our barbarous ancestors'.

\section{Models of Mind}

What is the character of these structures of signs, our beliefs? Our claim here is that Peirce has provided us with a model of mind, a model of cognition that was largely overlooked or incomprehensible until an instantiation of it was readily available. Prior to this our models of cognition were guided by a series of metaphors like Thorndike's telephone switchboard. No one can doubt the impact that computer technology has had on our philosophical and psychological conceptions of mind $^{2}$, yet only recently has a technology emerged that approaches the radical generativity of Peirce's model of semiosis. We would like to review briefly two dominant computer metaphors of mind before presenting a third that has recently emerged.

First is the notion of the mind as a symbol manipulator (SM), the basic premise underlying traditional artificial intelligence but also much of instructional design and development. SM assumes that the mind is an instantiation of a Turing machine, a symbol manipulation (e. g. Newell and Simon's General Problem Solver ${ }^{3}$ ) device in which every cognitive process is algorithmic in the same sense that computer processes are algorithmic; that is, the mind works by processing symbols according to rules. These symbols are entirely abstract and independent of any given individual's experience of them; i.e., the operation of the mind is completely independent of the person in whom it is contained. Meaning is mapped on to these symbols via our experiences in the world in a mind-independent manner. Our understanding of the world is formed from a process of interacting with, discovering reality "out there" and transferring that understanding into the mind, forming internal representations that determine our subsequent interactions with the environment. Symbols

1 Ibid, 2.302.

2 E.g. G. Shank and D.J. Cunningham, Modeling the six modes of Peircean abduction for educational purposes, Paper presented at the annual meeting of the Midwest AI and Cognitive Science Conference, Bloomington, Indiana, April 1996 ; D.J. Cunningham, "Cognition as semiosis: The role of inference", op. cit.

3 A. NewELl and H. Simon, Human problem solving, Englewood Cliffs, NJ, Prentice Hall, 1972. 
(or concepts) derive their meaning from their capacity to match (to a greater or lesser extent) aspects of reality. Any individual's internal representation will certainly depart from reality, but it does seem necessary to assume that, in principle, there must exist a conceptual framework which is entirely general and neutral, a single correct, completely objective way of representing the world. Learning is a process of information acquisition, processing according to innate or acquired rules, and storage for future use.

More recently cognitive scientists have proposed a metaphor of mind as a network (NET) of simple processing units, a view variously called connectionism or parallel distributed processingl. Connectionist models assume that symbols are learned consequences of particular experiences or interactions in the world which are then mapped on or distributed across neural-like networks. Connectionism seeks to avoid the limitations of the SM view and capitalize on precisely the experiential character of human concepts. It also deliberately links with our emerging knowledge of brain function; e.g., the brain would have to do massively parallel processing to accomplish even the most ordinary cognitive act, let alone the serial operations proposed by SM models. Connectionism is the notion that intelligence emerges from the interactions of large numbers of simple processing units. Representations are not localized in some general purpose symbol; rather they are distributed throughout a network of simple processing units according to patterns of activation which have emerged as a result of experience. Unlike SM models, knowledge is not stored as a static copy of a pattern in long term memory with no real difference between what is retrieved and stored in working memory. Representation is an active process. What is stored in connectionist models are connection strengths between units that allow these patterns to be recreated (re-presented or reconstructed). Consequently, learning is "a matter of finding the right connection strengths so that the right pattern of activation will be produced under the right circumstances..., as a result of tuning of connections to capture the interdependencies between activations that the network is exposed to in the course of processing"2.

\footnotetext{
1 See, for example, D. Rumelhart and J. MCClelland, Parallel distributed processing, Cambridge, 1986.

2 Ibid., p. 32.
} 
SM and NET models are alike in that both characterize mind as separate from the environment and as information processing bound within individuals. A major difference is that knowledge is a matter of storage and retrieval according to rules in the SM view, but a function of distributed connection strengths and network activation for the NET position. It is this difference which sets the stage for the possibility of some fresh thinking about the teaching/learning process.

The alternative we wish to propose here builds upon Peirce's notion of unlimited semiosis. The mind is extended beyond the brain and directly into the action of signs. Here we deliberately blur or obliterate such common distinctions as environment/individual, inside/outside, and self/other. Loosely speaking, our work -primarily the blurring of brain/environment boundaries- places us in the emerging situated, or distributed, cognition domain ${ }^{1}$. But our concept of the nature and spread of distribution with an emphasis on signs and inference as constituting semiosis takes us far beyond most models of distributed or situated cognition. Elsewhere $\mathrm{we}^{2}$ have labeled this view MIND AS RHIZOME (RZM), a metaphor inspired by Umberto $\mathrm{Eco}^{3}$.

A rhizome is a root crop, a prostrate or underground system of stems, roots, and fibers whose fruits are tubers, bulbs and leaves. A tulip is a rhizome as is rice grass, even the familiar crab grass. The metaphor of rhizome specifically rejects the inevitability of such notions as hierarchy, order, node, kernel, or structure. The tangle of roots and tubers characteristic of rhizomes is meant to suggest a form of mind where 1) Every point might and can be connected with every other point, making infinite juxtaposition possible, 2) There are no fixed points or positions, only connections (relationships between seeming points which only reveal more relationships upon closer inspection), 3) The structure is dynamic, constantly changing, such that if a portion of the rhizome is broken off at any point it could be reconnected at another point, leaving the original potential for juxtaposition in place, 4) There is no hierarchy or genealogy

1 See, for example, Whitson's chapter in D. KIRSHNER and J. WhITSON, Situated cognition: Social, semiotic, and psychological perspectives, Mahwah, NJ, Erlbaum, 1997.

2 E.g. D.J. Cunningham, "Beyond educational psychology: Steps toward an educational semiotic", Educational Psychology Review, ${ }^{\circ}$ 4, 1992, pp. 165-194.

$3 \mathrm{U}$. ECO, Semiotics and the philosophy of language, Bloomington, IN, Indiana University Press, 1984; see also G. Deleuze and F. GuatTaRI, "Rhizome", in G. Deleuze and F. GuATTARI (eds), On the Line, New York, Semiotext(e), 1983. 
contained as where some points are inevitably superordinate or prior to others, and 5) The rhizome whole has no outside or inside, but is rather an open network which can be connected with something else in all of its dimensions.

The notion of a rhizome is a difficult one to imagine because we so quickly try to impose latent SM or NET frameworks on it, and because any attempt to statically picture one risks minimizing its dynamic, temporal, and even self-contradictory character. Eco ${ }^{1}$ has labeled the rhizome as "an inconceivable globality" to highlight the impossibility of any global, overall description of the network. Since no one (user, scientist or philosopher) can describe the whole, we are left with "local" descriptions, a vision of one or a few of the many potential structures derivable from the rhizome. Every local description of the network is a hypothesis, an abduction constantly subject to falsification. To quote Eco:

Such a notion (...) does not deny the existence of structured knowledge; it only suggests that such a knowledge cannot be recognized and organized as a global system; it provides only "local" and transitory systems of knowledge which can be contradicted by alternative and equally "local" cultural organizations; every attempt to recognize these local organizations as unique and "global"-ignoring their partiality-produces an ideological bias ${ }^{2}$.

This last statement emphasizes the point that we are not proposing the metaphor of rhizome for an individual mind, but to minds as distributed in social, cultural, historical and institutional contexts. Except as a degenerate case, there is no such thing as a single mind, unconnected to other minds or to their (collective) social cultural constructions. Thinking, or whatever we choose to call the activity of mind, is always dialogic, connected to another; either directly as in some communicative action or indirectly via some form of semiotic mediation-signs and/or tools appropriated from the sociocultural context.

We are connected to other people individually but also collectively as in the speech communities or social languages in which we are all embedded. We are connected to the sociocultural milieu in which we operate, a milieu characterized by the tools

1 U. ECO, op. cit., p. 83.

2 Ibid., p. 84. 
(computers, cars, television, and so forth) and sign systems (language, mathematics, drawing, etc.) which we may appropriate for our thinking. Thus thinking is not an action which takes place within mind within a body, but rather at the connections, in the interactions. But it is worth saying again that this thinking is always "local", always a limited subset of the potential (unlimited) rhizomous connections.

Learning, then, is neither a matter of learning the symbols of the world and the rules for manipulating them, nor of activating the right connections in the brain. It is, rather, a matter of constructing and navigating a local, situated path through a rhizomous labyrinth, a process of dialogue and negotiation with and within a local sociocultural context. In his popular novel The Name of the Rose, Umberto Eco' describes a medieval library, a labyrinth of passages, stairways and chambers filled with books. The library is a thizome (as much as any actual existent thing can represent "an inconceivable globality") and learning is illustrated by Brother William, the main character of the novel, feeling and groping his way through the library. As Brother William constructs a path (or pattern of connections) through the library, one of only many possible paths, he is transforming his means of participating in the community of scholars, both those using the library (constructing their own paths) and those who have written manuscripts contained therein. Brother William is thereby learning the activities that will allow him to be effective in that community - to become a site for additional semiosis. In our view, he is not acquiring and internalizing, not building an abstract mental representation of the library and its contents. He simultaneously constitutes and is constituted by rhizomatic growth.

The notion of an unlimited potential for semiosis as embodied in the metaphor of rhizome has been largely ignored in cognitive theory ${ }^{2}$. No doubt the comparison of mind with a root crop was problematic (we did suffer the unkind comparison with $\mathrm{Mr}$. Potato Head more than once). But the advent of the World Wide Web has provided a propitious moment for the ascendancy of Peirce's theory. While the "results" of a connection to WWW is experienced via an interface with one's local workstation, that experience is possible only as a result of connections with many (potentially an infinite number)

1 U. Eco, The name of the rose, W. Weaver (trans.), New York, Harcourt, Brace and Jovanovich, 1983.

2 With some welcome exceptions like M. Driscoll, Psychology of learning for instruction, Needham Heights, MA, Allyn \& Bacon, 2000. 
of servers all over the world. The local workstation both contributes to (constructs) and is constructed by its connections. This is precisely the sort of connectivity and potential envisioned for the rhizome ${ }^{1}$.

\section{Mathematical Problem Solving as Semiosis}

In taking our rhizome model closer to the classroom we report on empirical semiotic studies of mathematical problem solving and use them to make pedagogical observations. In the discussion below we hope to give the flavor of what a cognitive semiotic lens can contribute to pedagogy beyond the empirical study of cognition. We studied problem solving in a mathematical-modeling context that begins with the identification of a problem in an initially nonmathematical context, or sign system. Often, as one gains an understanding of the problem, specific mathematical representations (mathematical sign systems) might be seen as useful in reasoning about the problem. By making simplifying assumptions and forming various abstractions between the original situation and a mathematical system, the original problem is transposed into a problem about a mathematical representation, or model -the problem is "mathematized". At this point, familiar patterns of mathematical inference can be applied and perhaps extended in efforts to solve the mathematical problem. Finally, the results of these mathematical manipulations must be interpreted in the context of the original problem to judge their validity.

Although the process just described seems very linear, there is in practice much back and forth movement between original problem context and various mathematical representations; however, note that if an expert mathematical modeler comes across a familiar problem for which there is a good known model, then there probably is a linearity to her thinking that reduces the problem to a mere exercise in application. This highly routine behavior is where other models of cognition enjoy some success - but a limited success that doesn't even attempt to reflect the greater globality of the rhizome. We are interested in what people do when confronted with a true problemnot a mere exercise. Consider the following problem and accompanying diagram in Figure 1.

1 This issue is discussed more comprehensevely in D.J. CUNNINGHAM, "Beyond educational psychology: Steps toward an educational semiotic", op. cit. 


\section{Alaskan Pipeline Problem}

The Alaskan oil pipeline consists of a network of pipes each with a maximum flow rate (e.g., barrels/second). Flow through the network must satisfy 3 rules:

i) flow is only allowed in the direction indicated on each pipe

ii) the actual flow in any pipe can not exceed the pipe's capacity

iii) the total flow arriving at a node must equal the total flow leaving the node

In the diagram of the pipeline below (numbers represent maximum flow capacities, and arrows indicate direction of flow), we are interested in the maximum possible flow through the networkfrom Prudhoe Bay to Seward. Find the maximum possible flow. Provide a proof that your solution is indeed the largest possible flow and/or a general algorithm (method) for finding the maximum flow in any network.

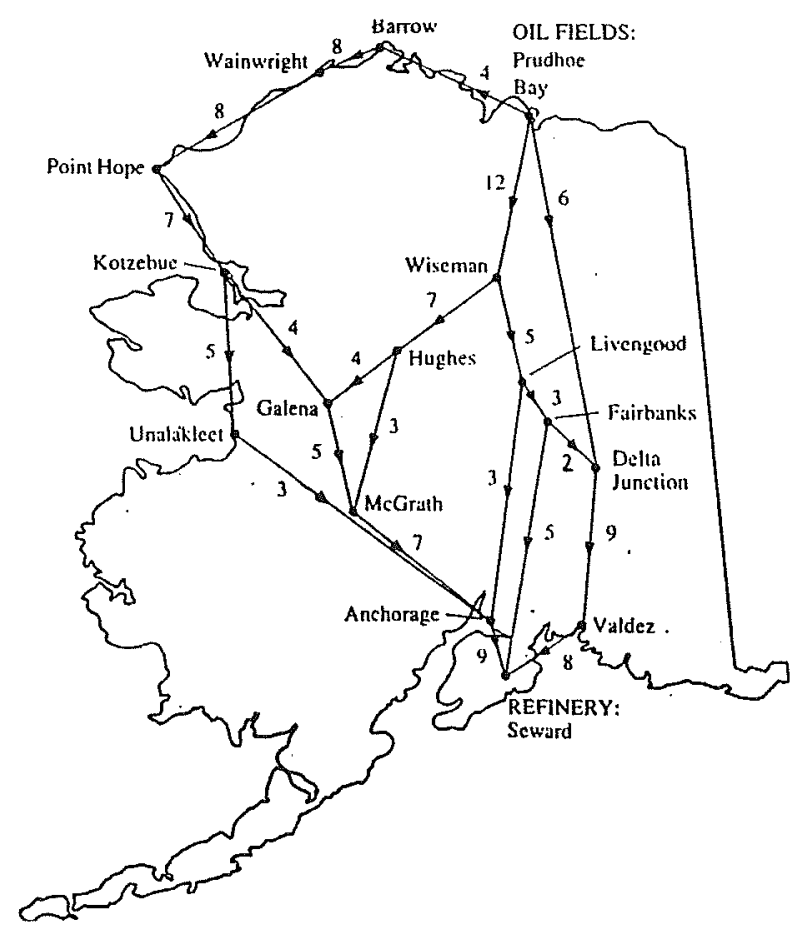

Figure 1. A network based on the Alaskan pipeline 
We studied ten groups, comprised of individuals or pairs of people, between 18 and 24 years of age, as they solved the above problem along with several others. Each problem solving session lasted between two and three hours; we were non-directive observers taking notes to supplement analysis of the video tapes and audio transcriptions of the problem-solving sessions. The methodology and results are presented in Kehle's dissertation ${ }^{1}$ and discussions are also found in Kehle and Cunningham ${ }^{2}$, and Kehle and Lester ${ }^{3}$.

Although some numbers are present in the original context, making the problem somewhat mathematical in flavor, there is no clear indication of what to do with the numbers in order to solve the problem. For most people, some abduction is called for before a model or way of working with the problem emerges. Some readers might recognize the problem setting as creating an opportunity for the discovery or construction of the Minimum Cut Maximum Flow theorem in the mathematical discipline of graph theory.

Our study of people's work on this and other problems relied upon semiotic parsings of video-taped problem-solving sessions. Our parsings sought to identify locally coherent sign systems, (i.e., structures) and the dominant inferential activity within and among these systems; attention was also paid to the dominating qualities (iconic, indexic, and symbolic) of the signs employed by the problem solvers; but here we focus on the role of inference and of abduction in particular. Figure 2 presents the work of a person who was very successful with the Alaskan Pipeline problem despite having very little knowledge of graph theory, and none specifically of network flow situations.

1 P. KEHLE, "An empirical semiotic analysis of abstraction in mathematical modeling", Dissertation Abstrats International, 60 (06A), 1949 (University Microfilms $\mathrm{N}^{\circ}$ AAG9932664), 1998.

2 P. Kehle and D.J. CunNINGHAM, "Semiotics and mathematical modeling", International Journal of Applied Semiotics, 3 (1), 2002, pp. 113-129.

3 P. KEHLE and F. LESTER, "A semiotic look at modeling behavior", in D. LESH and H. DOERR (eds), Beyond constructivism: models \& modeling perspectives on mathematics problem solving, learning and teaching, Hillsdale, NJ, Erlbaum, 2002. 


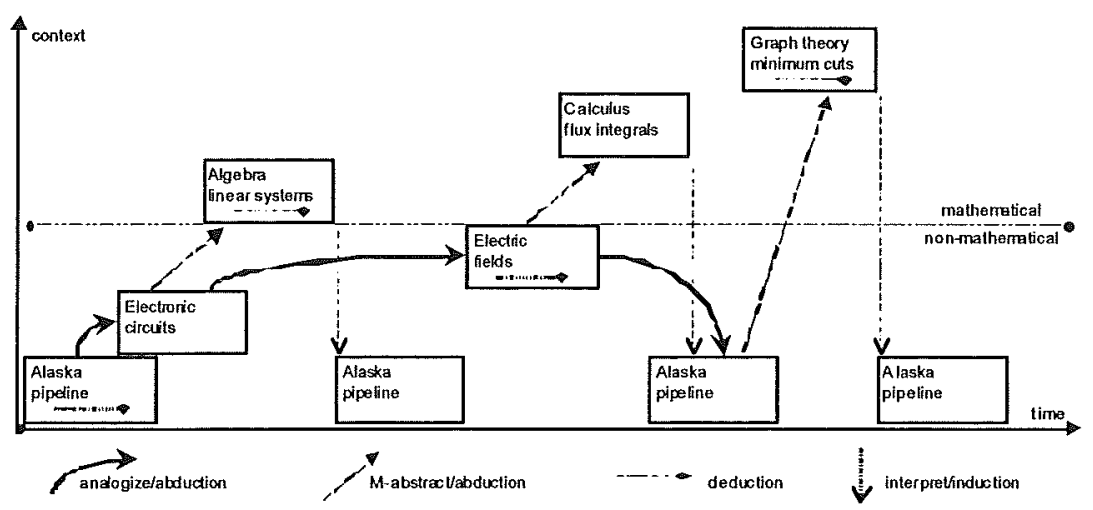

Figure 2. Contextual inferential parsing of Abe's work on the Alaska pipeline problem

One of the foci of our work was examination of the generation of mathematical representations for working on the problem, and hence, these types of abductions are distinguished from other abductive moves in the context parsing in Figure 2. For our present purposes, note that all of these abductions are similar in that they are tentative attempts to make sense of unfamiliar situations, and that they all involve some analogical basis.

The analogical basis of abduction is perfectly revealed in Abe's [a pseudonym] first reaction to the map of Alaska when he declared that it "looks like an electric circuit with resistances on wires," knowing fully that it was not a circuit. This metacognitive awareness of the nature of rhizomatic connection Abe was making is another strength of our semiotic model and its fidelity to cognition's ability to reflect upon its own activity. Note that both SM and NET models would likely lead to unrecoverable failures at this point because of a category error. But in casting about for something more familiar than pipelines, Abe made a rhizomatic connection -equally rich in future generative capacity and abductive tentativeness- between electric circuits and pipelines. We suspect that the iconic similarity of the two images (one real, the other brought to consciousness from memory) drove this connection which then led to the possibility of somehow treating the pipeline problem as a system of simultaneous equations of the sort used to solve electric-circuit problems. This move is not inductive because the role of pipe capacities is opposite to that of resistor resistances. This gap is precisely where the analogy doesn't fit perfectly and why there is an analogy at all -in this sense a perfect 
analogy cannot exist because were the resemblance between two things is perfect then we simply have two instances belonging to the same category.

The generative power of free-wheeling rhizomatic connections lies in the analogic space between two things. It is in this space that semiosis or cognition occurs. A focus on this analogical gap entails a subtle shift in understanding cognition that moves us beyond the SM and NET mind-experience duality. The shift recognizes that cognition is inseparable from the signs (e.g., for pipelines, circuits, and equations), interpretants (i.e., the nature of the potential inferential connections among these signs within Abe), and the given structure in the pipeline context. In Eleanor Duckworth's language ${ }^{1}$, Abe had a "wonderful idea" of the sort that is not aimed for in traditional approaches to the development of rote or mastery learning. We contend that it was Abe + environment that gave rise to the wonderful idea and that it is this broader site that is the proper focus of cognitive study and pedagogical intervention.

Return to Figure 1 for a moment, and consider that the box labeled "graph theory minimum cuts" unlike several of the other context boxes was a wholly new site of inferential activity for Abe. His work on this problem was exceptional in the degree of clarity with which he constructed the Min-Cut-Max-Flow theorem. Abe was not unique however in his ability to construct this understanding; however, most other successful problem solvers took much more convoluted paths toward the final result. Abe's efficient navigation of the analogical spaces was what distinguished his work rendering a textbook example of abductive sense-making.

A SM or NET metaphor would downplay the role of the analogical gap and perhaps even view it as a hurdle to the top-down teaching of the Min-Cut-Max-Flow theorem, or to the training of a person to its use and subsequent recall in appropriate situations. The power of human thought lies in the forming of novel connections and their reflexive evaluation, and we believe both Abe's understanding of network flow and his capacity for solving future novel problems are richer for his rhizomatic activity in the analogical gaps he navigated while working on the pipeline problem. Furthermore, we point out that for any student first encountering any "topic", she is engaged in

1 E. DuCKworTH, The having of wonderful ideas and other essays on teaching and learning (2nd ed.), New York, NY, Teachers College Press, 1996. 
navigation of analogical gaps that are initially unknown to her and her teachers -she is engaged in abduction. A "topic" becomes a topic only with hindsight and much experience, and it is a mistake to ignore, and even worse to rush or prepackage the acquisition of this hindsight and experience in educational settings. The result is often a lifeless inert bunch of facts or skills. Instead, teachers and students need all focus more on the nature of their inferential movement and what it reveals about their inextricable connections with environment.

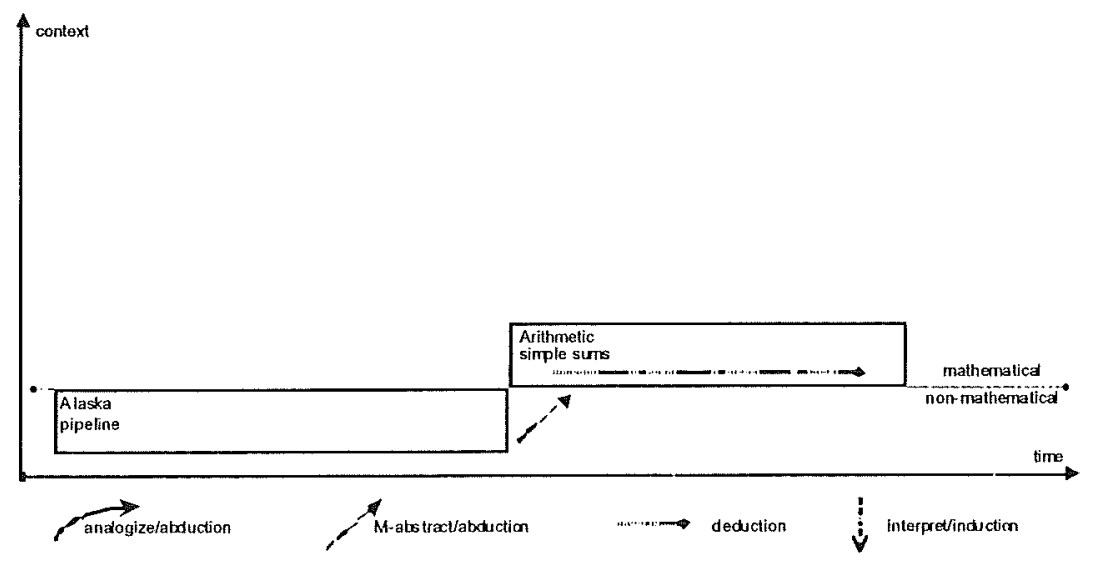

Figure 3. Context parsing of Ann and Bev's work on the Alaska pipeline problem

Briefly, compare the work in Figure 3 with that in Figure 2. What is most notable about this unsuccessful work on the Alaska pipeline problem, is the absence of analogy-sustaining intermediate contexts, the absence of attempts to interpret their mathematical results (inductive moves), and a very limited range cognitive activity in general. Although the initial problem context was also unfamiliar to them (as it was to Abe), they chose to work in a very familiar mathematical context and resisted proddings to examine their work more closely. They were satisfied with their work on the problem. We believe their work to be typical of unsuccessful modelers who try to blindly apply inert knowledge to a problem -forcing a fit that might not be good- out of desire for the comfort offered by familiar deductive manipulations they take to be mathematics. Recall Peirce's of the unease and discomfort brought about my doubt. We suspect that Ann and Bev differ greatly from Abe in the degree to which they 
understand the role of some cognitive dissonance $-\mathrm{a}$ degree that matches the gap in their sense-making abilities.

What is to be gained from the RZM metaphor? Mary Catherine Bateson captures the role analogy and metaphor play in human sense making and learning: "The solution is not to purge metaphors from speech and try to ignore them; the solution is to take responsibility for the choice of metaphors, to savor them and ponder their suggestions, above all to live with many and take no one metaphor as absolute"'. In setting the RZM, SM, and NET metaphors beside each other, a juxtapositioning technique urged by Bateson ${ }^{2}$, what do we find? The part of cognition that SM gets right, is the role of limited memory and sign recognition -the ability to not have to always look up the word "word" when we see it. A NET approach helps us understand why some signs might trigger some inferential moves rather than others, and it begins to help us see the role of connections. What the RZM metaphor adds to the mix is the unlimited nature of the connections that make semiosis pragmatic beyond the initially prescribed and proscribed types of inputs and outputs a neural network is constrained by; and that more fully captures the bottom-up trajectory of sense making in contrast to the top-down training of rules for symbolic manipulation.

The individual symbol's degree of match with some aspect of reality in the SM model gives way to a RZM notion of fidelity of the relationships among an extended sign system and its associated inferential patterns with those aspects of reality this sign system helps us make sense of. Our notion of truth is implicated by a semiotic perspective that joins thought, sign and environment so intimately. Truth as correspondence between representation and object makes less sense when representation and object and thought are one at the deeper level we suggest. We are left with a notion of truth that is much more pragmatic (Peirce wouldn't object!) and closer to the fidelity among patterns of inference within a local sign system. By fidelity we do not mean loyalty to another, but rather the mutuality of relationships that results in sustainability or persistence: ways of thinking that prove useful both within given contexts and as points of future analogical gap creating and navigating. This fidelity reveals as

I M.C. BAtEson, Peripheral visions: Learning along the way, New York, Harper Collins Publishers, 1995, p. 141.

2 Ibid. 
it is shaped by the constraints on semiosis in a particular setting: the Peircean notion of finding "out what must be and not merely what is in the actual world"'. Josephson and Josephson's ${ }^{2}$ characterizing of abduction as truth generating, deduction as truth preserving, and induction as truth confirming needs to be taken to heart not only at the societal or cultural level at which Einstein's $\mathrm{E}=\mathrm{mc}^{2}$ is relevant but also at the individual level at which Mary's making sense of what $1 / 2$ of $3 / 8$ is, or of how a pendulum works, or of what "freedom" means all begin with abduction and not with her teacher's -influenced by long term familiarity-inductive understanding of these things.

Constructivism is a popular pedagogical model within educational circles today ${ }^{3}$, but constructivism requires more explicit frameworks for helping teachers and students develop powerful strategies and practices for creating, manipulating, and interpreting sign systems they are tangled in-inextricably so. Other than a partial freeing, often in unspecified ways, of students from the traditional narrowing of semiosis to an imitation and regurgitation of a limited two-fold understanding of signification, constructivism often fails to provide guidance when in fact it can. Cognition viewed through a semiotic lens can provide this guidance. Below are highlights of what we are finding characterize not only good problem solvers, but good learners as well; and these traits are ones that bear closer attention on the parts of both students and their teachers.

\section{Drawing Upon Developed Sign Systems-Juxtapositions}

Successful problem solvers drew upon familiar, well-developed sign systems. Although part of the genius afforded us by semiosis lies in our ability to abduce or structure novel sign systems as we agree upon various signifying acts, more-successful problem solvers initially juxtaposed more familiar contexts with the original problem. The less-successful participants often failed to bring much in the way of other knowledge that they possessed to the problem, and instead,

C.S. PEIRCE, op. cit., 2.227, emphases in original.

2 J. JOSEPHSON and S. JOSEPHSON, Abductive inference: Computation, philosophy, technology, Cambridge, Cambridge University Press, 1994.

3 E.g. T. DUFFY and D.J. CUNNINGHAM, "Constructivism: Implications for the design and delivery of instruction", in D. JONASSEN (ed.), Handbook of Research on Educational Communications and Technology, New York, Macmillan, 1996, pp. 170-198. 
restricted their sense making to the original problem statement (e.g., Ann and Bev). The extent of a person's familiarity with the juxtaposed sign system corresponded to the comprehensiveness of their final solutions. On those rare occasions where participants generated what was for them new mathematics, this generation occurred only after a long period of work with more familiar sign systems, suggesting that such novel behavior is preceded by reflective work within familiar sign systems -novelty is born out of familiarity.

\section{Seeking Out and Tolerating Multiple Levels of Significance}

Once intentional juxtapositioning is underway, or implicit juxtapositions have been taken note of, the more successful problem solvers simultaneously entertained many possible ways of making sense of and approaching the problems. One person epitomized this aspect of reflexive attention by sometimes interrupting himself to generate new possibilities. His partner sometimes cut short his juxtapositioning by pleading with him to stick to one thought. Mind as rhizome is not afraid of making lots of connections, and in fact needs them for growth.

\section{A Playful Disposition Toward Signs}

A more subtle and subjective aspect of a reflexive awareness of one's inferential activity concerns the general dispositions of problem solvers toward their work. More successful problem solvers tended to display a playful disposition that reflects an intrinsic enjoyment in considering what different ways of thinking about a problem have to offer. Accompanying this playfulness was a background assumption that playing with signs in different ways was pragmatic. This playfulness was most pronounced when someone had an insight leading to a new way of thinking about a problem and became excited as a result. How often is time made for this kind of serious play in today's classrooms? How often are students encouraged to pursue tentative understandings (often seen as an inefficient use of time) that in turn will give rise to understandings of greater fidelity and persistence (Peirce's fixing of belief)?

In conclusion, perhaps we should simply rephrase one of the grandfathers of the study of mathematical problem solving, George 
Polya, turning his dictum that we "teach guessing" into "let us teach and study abduction"-in so far as teaching means providing opportunity for the exercise of abduction and the reflexive analysis of it. Placing inference and abduction at the center of classroom discourse requires us to reconsider such traditional top-down notions of scope and sequence, objectives, the nature of mastery learning, and what it is exactly that learners are constructing when engaged in various activity. How can the space be created in hectic schools for the serious tentative play that gives rise to sense? A semiotic perspective can help guide educators as they take the most significant step: making the act of learning, (i.e., semiosis) as much a focus of classroom discourse as is any particular topic or objective on the syllabus. The time for semiotic's ability to serve as both method and meta-method has come. 